\title{
RAZLIČITOST PROCESA SUŠENJA I REŠENJA KONDENZACIONIH SUŠARA I SUŠARA SA TOPLOTNOM PUMPOM
}

\author{
DIVERSITY AND DRYING SOLUTIONS CONDENSATION DRYERS \\ AND DRYERS WITH HEAT PUMP
}

\author{
Radivoje M. TOPIĆ( ${ }^{1)}$, Milovan ŽIVKOVIĆ ${ }^{2)}$, \\ Jelena R. TASIĆ(3), Goran R. TOPIĆ ${ }^{4)}$, \\ ${ }^{1)}$ Mašinski fakultet Univerziteta u Beogradu, Beograd; \\ ${ }^{2)}$ Capotto Build, Beograd; \\ ${ }^{3)}$ Energoprojekt, Beograd; \\ 4) Srbijagas, Beograd \\ rtopic@mas.bg.ac.rs; zivkovic.cappotob@fashioncompany.rs; \\ Jelenat2280@gmail.com; goran511@gmail.com
}

Pošto se u literaturi (većina literaturnih izvora) i praksi (većina proizvođača i korisnika) poistovećuju rešenja i procesi u kondenzacionim sušarama i sušarama sa toplotnom pompom, tačnije ne pravi se razlika sa aspekta konstrukcije rešenja i odgovarajućih procesa, u radu se razmatraju, analiziraju i upoređuju rešenja ovih sušara i procesa: sa delimičnom recirkulacijom i potpunom recirkulacijom agensa sušenja, kondenzacionih sušara, $i$ procesa sušenja u sušarama sa toplotnom pompom.

Ključne reči: sušenje, sušara, kondenzaciona sušara, sušara sa toplotnom pumpom

Since the literature (most literature sources) and practices (most manufacturers and users) identify solutions and processes in condensation dryers and dryers with heat pomp, more precisely, there is no distinction in terms of construction solutions and related processes at work are considered, analyzed and compared solutions such dryers and process with partial recirculation and full recirculation of the drying agent, condensing dryers and drying in dryers with heat pump.

Keywords: drying, dryers, condensing dryers, dryers with heat pump

\section{Uvod}

U procesu sušenja se koriste različiti načini sušenja sa aspekta postupka sa izrađenim agensom sušenja $\mathrm{i}$ to: sa delimičnom recirkulacijom izrađenog agensa sušenja; sa potpunom recirkulacijom izrađenog agensa sušenja; korišćenjem toplotne pumpe i drugi.

Delimična recirkulacija agensa sušenja koristi se, po pravilu, za sušenje dasaka, različitih proizvoda od drveta i keramike koji zahtevaju, da bi se izbegle mehaničke promene materijala, agens sušenja veće relativne vlažnosti.

Pri radu bez delimične recirkulacije neophodno bi bilo vazduh vlažiti pre ulaska u komoru za sušenje i trošiti za to dodatnu energiju.

Kad materijali zahtevaju naročito čist vazduh (bez prašine i nekih hemijskih primesa) mora se pristupiti prethodnom čišćenju pred ulazak u komoru za sušenje. Ovo prečišćavanje je vezano sa troškovima pa je šteta tako pripremljen agens sušenja pustiti u atmosferu na kraju procesa sušenja. Bar jedan deo toga vazduha može se ponovo vratiti u proces. Njemu se mora dodavati i svežeg vazduha koji treba da ima manju vlažnost kako bi i dobijena smeša bila dovoljno suva i sposobna da primi izdvojenu vlagu iz materijala. U ovom slučaju se koristi proces sušenja po zatvorenom toku sa kondenzacijom vodene pare i drugih hemijskih supstanci. Ovaj proces sušenja se pre svega koristi za sušenje inertnim gasovima kao agensom sušenja , materijala koji oksidišu na vazduhu. Za sušenje vazduhom, zatvoreni ciklus se koristi pri povećanim zahtevima čistoće agensa sušenja, ili pri neophodnom odnošenju štetnih primesa, koje se zbog zaštite okoline ne izbacuju u atmosferu.

Primena toplotne pumpe u procesima sušenja dolazi u obzir na lokacijama jeftine električne energije i gde je dopremanje drugih vidova goriva otežano. Ovim načinom se postižu uštede u specifičnoj potrošnji toplotne energije, međutim potrebna su dodatna finasijska sredstva za dodatnu opremu. 


\section{0..Sušare sa delimičnom recirkulacijom agensa sušenja}

Šema sušare s delimičnom recirkulacijom izrađenog agensa sušenja u cilju ponovnog korišćenja pri recirkulaciji izrađenog agensa sušenja, sa ili bez ventilatora je prikazana na sl.1a.. Proces sušenja u $\mathrm{x}-\mathrm{h}$ dijagramu je prikazan na sl.1b.. Posle napuštanja komore za sušenje izrađeni agens sušenja, parametara koji odgovaraju stanju $\mathrm{C}$, se razdvaja na dva dela: deo izrađenog agensa sušenja se ispušta u atmosferu a deo se ponovo vraća u komoru za sušenje. Pre toga meša se sa masom svežeg vazduha parametara koji odgovaraju stanju u tački A, koja odgovara masi ispuštenog u atmosferu izrađenog agensa sušenja. Dobijena smeša, parametara koji odgovaraju stanju $M$, se zagreva u zagrejaču, do stanja koje odgovara stanju $B_{1}$, i ulazi u komoru za sušenje. Po izlazu iz komore za sušenje protok izrađenog agensa sušenja se ponovo deli i dalje se proces ponavlja. $\mathrm{U} \mathrm{x}-\mathrm{h}$ dijagramu proces $\mathrm{u}$ teorijskoj sušari predstavljen je linijom $\mathrm{AMB}_{1} \mathrm{C}_{1} \mathrm{M}$.
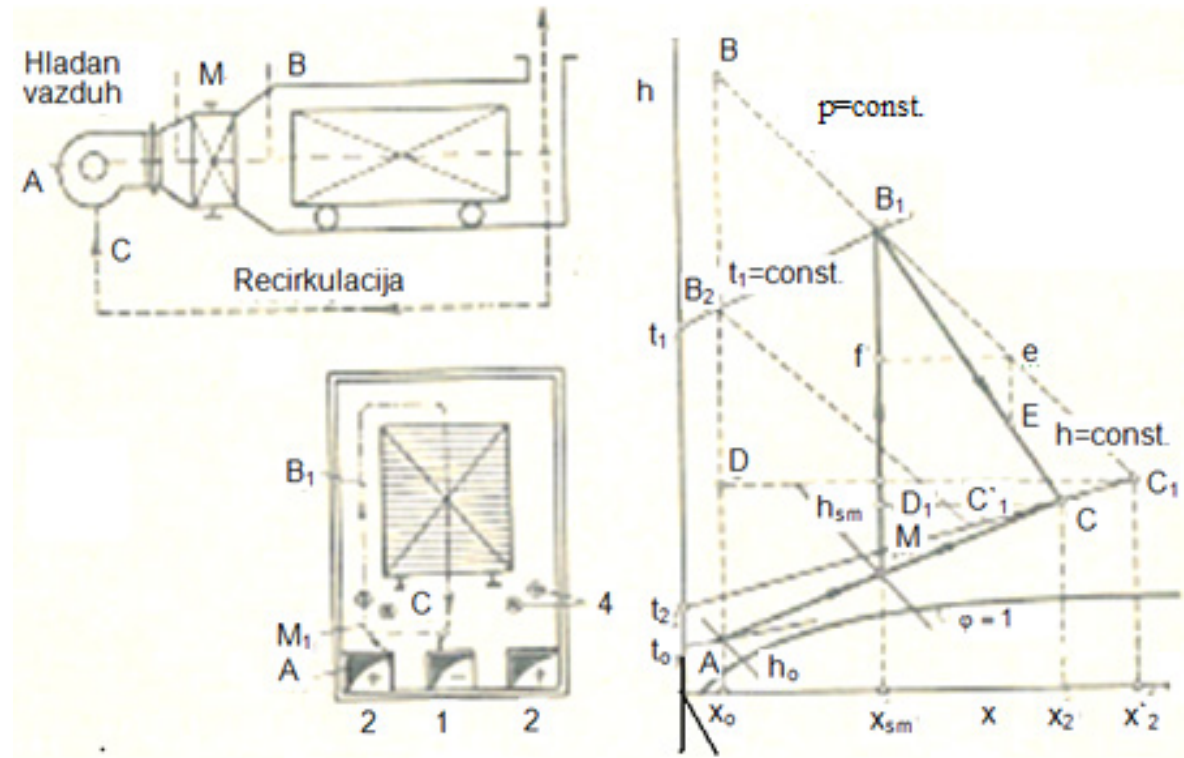

Sl.1. Sušara sa delimičnom recirkulacijom izrađenog agensa sušenja

a) Šema sistema, sušare sa prinudnom cirkulacijom; b) šema procesa sa prirodnom cirkulacijom;

c) proces sušenja u $x$ - $h$ dijagramu

Specifične potrošnje apsolutno suvog vazduha u svežem i izrađenom agensu sušenja su jednake i definišu se izrazom:

$$
1=\frac{1}{\mathrm{DC}_{1} \mathrm{M}_{\mathrm{x}}}=\frac{1}{\mathrm{x}_{2}^{\prime}-\mathrm{x}_{\mathrm{o}}}
$$

jer izdvojena vlaga odlazi sa izrađenim agensom sušenja.

Protok agensa sušenja, vazduha, u komori za sušenje se definiše uslovom da se $1 \mathrm{~kg}$ smeše povećava apsolutna vlažnost od $\mathrm{x}_{\mathrm{sm}}$ do $\mathrm{x}_{2}{ }_{2} \mathrm{i}$ iznosi:

$$
1_{c}=\frac{1}{D_{1} M_{x}}=\frac{1}{x_{2}^{\prime}-x_{s m}}
$$

Kako se vidi iz izraza (2) povraćaj izrađenog agensa sušenja znatno povećava protok agensa sušenja, rezultat čega je i povećanje snage ventilatora.

Pošto je $\mathrm{AB} / \mathrm{DC}_{1}=\mathrm{MB}_{1} / \mathrm{D}^{\prime} \mathrm{C}_{1}$ specifična potrošnja toplote je:

$$
\mathrm{q}=1 \cdot\left(\mathrm{h}_{1}-\mathrm{h}_{\mathrm{o}}\right)
$$

Korišćenje delimične recirkulacije omogućava vođenje procesa sušenja pri visokim vrednostima relativne vlažnosti agensa sušenja bez potrošnje energije za njegovo vlaženje. Osim toga pri delimičnoj recirkulaciji je moguća fina regulacija vlažnosti vazduha na ulazu u komori za sušenje, a zahvaljujući smanjenju razlike temperature na ulazu i izlazu komore za sušenje poboljšava se kvalitet osušenog 
materijala. U nizu slučajeva delimičnu recirkulaciju agensa sušenja je celishodno primeniti i za materijale koji ne zahtevaju proces sušenja pri velikoj vrednosti relativne vlažnosti agensa sušenja. Korišćenje delimične recirkulacije u poređenju sa jednoprolaznim, jednokratnim korišćenjem agensa sušenja za teorijske procese, koji se odvijaju pri istim ulaznim i izlaznim parametrima, ali različitim početnim temperaturama agensa sušenja ne obezbeđuje uštedu energije pošto su trouglov $\mathrm{ABC}_{1} \mathrm{i} \mathrm{MB}_{1} \mathrm{C}_{1}, \mathrm{sl} .1$, slični. Ako se uporede teorijski procesi sušenja sa jednokratnim korišćenjem i delimičnom recirkulacijom agensa sušenja pri jednakim početnim i krajnjim temperaturama agensa sušenja (trouglovi $\mathrm{AB}_{2} \mathrm{C}_{1}{ }_{1}$ i $\mathrm{MB}_{1} \mathrm{C}_{1}$, sl.1.) u tom slučaju varijanta procesa sa delimičnom recirkulacijom agensa sušenja će zahtevati manju vrednost energije, pošto će ugao nagiba linije $\mathrm{AC}_{1} \mathrm{u}$ odnosu na apscisu biti manji od ugla nagiba linije $\mathrm{AC}_{1}{ }_{1} \mathrm{i}$ u tom slučaju je: $\mathrm{AB}_{1} / \mathrm{CD}_{1}\left\langle\mathrm{MB}_{1} / \mathrm{DC}_{1}\right.$

Pri izboru stepena recirkulacije, koji predstavlja odnos povraćene energije, i ukupne energije potrebne za sušenje i drugih eksploatacionih troškova, uštedu energije neophodno je uporediti s povećanjem energije za pogon ventilatora pri recirkulaciji dela agensa sušenja, koji zahteva ventilator većeg kapaciteta. Takođe $\mathrm{u}$ istoj meri treba uzeti u obzir i razliku u investicionim troškovima pri izvođenju procesa sa delimičnom recirkulacijom ili bez. Prikaz $\mathrm{u} \mathrm{x}-\mathrm{h}$ dijagramu procesa sušenja za stvarnu sušaru izvodi se isto kao i za proces sa jednokratnim korišćenjem agensa sušenja, nanoseći po vertikali od proizvoljnog stanja na liniji $\mathrm{BC}$ odgovarajući odsečak eE $=$ ef $\cdot \Delta / \mathrm{m}$ i povlačeći iz stanja $\mathrm{B}_{1}$ politropu stvarnog procesa sušenja $B_{1} C_{1}$ do zadate vrednosti temperature $t_{2}$ ili relativne vlažnost $\varphi_{2}$.

Unutrašnji bilans sušare je:

$$
\Delta=\mathrm{c}_{\mathrm{w}} \cdot \vartheta_{1}-\left(\mathrm{q}_{\mathrm{m}}+\mathrm{q}_{\mathrm{tr}}+\mathrm{q}_{5}\right) .
$$

Za stvarni proces sušenja s delimičnom recirkulacijom izrađenog agensa sušenja specifična potrošnja apsolutno suvog agensa sušenja u svežem vazduhu i izrađenom agensu sušenja je:

$$
\mathrm{l}_{\mathrm{o}}^{\mathrm{s}}=\frac{1}{\mathrm{x}_{2}-\mathrm{x}_{\mathrm{o}}}
$$

Specifična potrošnja apsolutno suvog vazduha u delu recirkulisanog izrađenog agensa sušenja je:

$$
l_{\mathrm{c}}^{\mathrm{s}}=\frac{1}{\mathrm{D}_{1} \mathrm{CM}_{\mathrm{x}}}=\frac{1}{\mathrm{x}_{2}-\mathrm{x}_{\mathrm{sm}}}
$$

Specifična potrošnja toplote je:

$$
\mathrm{q}=\frac{\mathrm{MB}_{1}}{\mathrm{D}_{1} \mathrm{C}} \cdot \mathrm{m}=\frac{\mathrm{h}_{1}-\mathrm{h}_{\mathrm{sm}}}{\mathrm{x}_{2}-\mathrm{x}_{\mathrm{sm}}}
$$

gde je $m=M_{h} / M_{x}$

\subsection{Sušare sa potpunom recirkulacijom izrađenog agensa sušenja}

Šema sušare sa zatvorenim tokom, potpunom recirkulacijom izrađenog agensa sušenja (ili što je pravilnije kazati kondenzacione sušare) za uslove prirodnog i prinudnog strujanja je prikazana na sl. 2a.

U kondenzatoru sa mešanjem dolazi do međudejstva vazduha i vode.

Kada temperatura vode dostigne temperaturu vlažnog termometra, proces ide dalje po pravoj liniji $t_{w}=$ const. $U$ nekim sušarama za sušenje gasova ili odnošenja iz njih skupih materija, koriste se takozvani apsorbenti, kao silikagel, aktivni ugalj i drugi. Za kontinualan rad neophodna su dva apsorbera (dok jedan radi, drugi se regeneriše).

Prema potrošnji toplote i elektroenergije, sušare sa zatvorenim ciklusom i kondenzacijom isparene vode su po pravilu, manje ekonomične od običnih konvektivnih sušara.

Izrađeni agens sušenja, nezasićen vlažan vazduh posle sušare se vodi na površinski ili kondenzator sa mešanjem, gde se hladi, gubi deo vlage, koju je uzeo od materijala, koja se kontinualno odvodi iz kondenzatora. Tako osušeni izrađeni agens sušenja se zagreva u zagrejaču do zahtevane, režimske 
temperature, i uvodi ponovo u komoru za sušenje, znači da ova sušara teorijski radi sa jednim istim agensom sušenja, vazduhom, bez izmene agensa sušenja, vazduha.

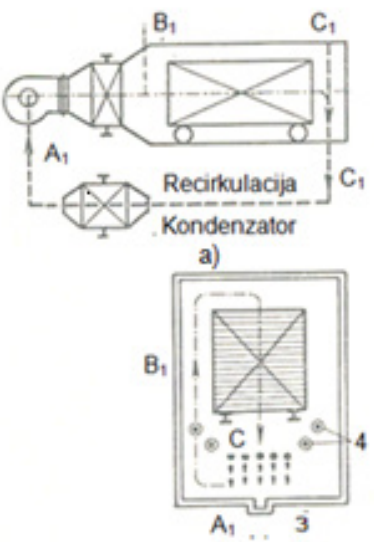

b)

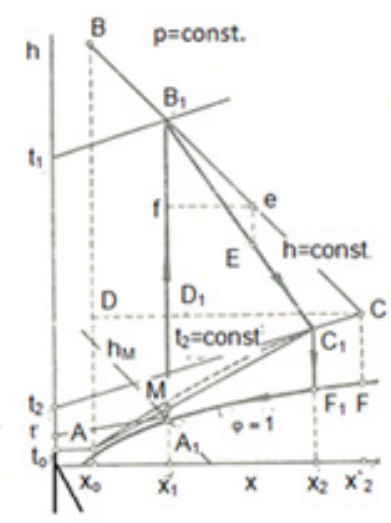

c)

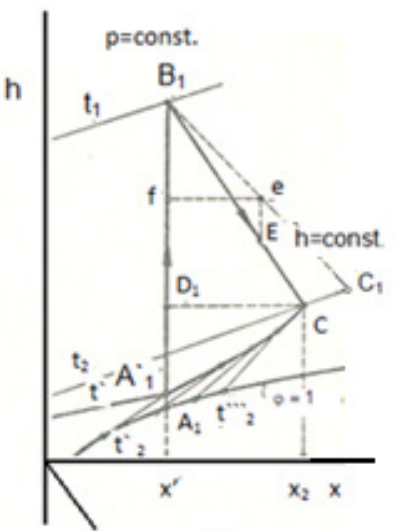

d)

Sl.2. Sušara bez izmene, agensa sušenja, vazduha

a) Šema sistema sa površinskim kondenzatorom; b) šema sistema sa kondenzatorom sa mešanjem; c) $i$ d) procesi $u x-h$ dijagramu

Pri zadatim parametrima $\left(t_{1}, \varphi_{1}, t_{2}\right)$ agensa sušenja posle izlazka iz komore za sušenje mora da se hladi do vrednosti temperature, koja bi obezbedila da njegova apsolutna vlaćnost posle kondenzacije na ulazu u komoru za sušenje bude jednaka $\mathrm{x}_{1}$. $\mathrm{U} \mathrm{x}-\mathrm{h}$ dijagramu proces za teorijsku sušaru sa površinskim kondenzatorom je prikazan linijom $\mathrm{A}_{1} \mathrm{~B}_{1} \mathrm{CFA}_{1}$ gde je $\mathrm{B}_{1} \mathrm{C}$ - proces u komori za sušenje, $\mathrm{CFA}_{1}$ - proces $\mathrm{u}$ kondenzatoru i $\mathrm{A}_{1} \mathrm{~B}_{1}$ - proces u zagrejaču agensa sušenja, vazduha. Proces u kondenzatoru $\mathrm{CFA}_{1}$ protiče s smanjenjem apsolutne vlažnosti po liniji $\varphi=1$ od $\mathrm{x}_{1}$ koje odgovara stanju $\mathrm{u}$ tački $\mathrm{B}_{1}$

Specifična potrošnja apsolutno suvog vazduha u procesu sušenja je:

$$
1_{c}=\frac{1}{\mathrm{CD}_{1} \mathrm{M}_{\mathrm{x}}}
$$

Specifična potrošnja toplote je:

$$
q=m \cdot \frac{A_{1} B_{1}}{C D_{1}}
$$

Ako se uporedi teorijski procesi kondenzacione sušare s površinskim kondenzatorom i sušare sa delimičnom recirkulacijom izrađenog agensa sušenja, pri jednom istom režimu sušenja, kondenzaciona sušara zahteva veću specifičnu potrošnju toplote, pošto je:

$$
\left.\frac{\mathrm{A}_{1} \mathrm{~B}_{1}}{\mathrm{CD}_{1}}\right\rangle \frac{\mathrm{MB}_{1}}{\mathrm{CD}_{1}}
$$

Osim toga pri ostalim istim uslovima kondenzaciona sušara zahteva veću ukupnu specifičnu potrošnju energije zbog neophodnosti uključivanja u šemu pumpe za odvođenje vlage sa površi kondenzatora.

Prikaz stvarnog procesa za kondnzacionu sušaru izvodi se kao i za sušaru sa delimičnom recirkulacijom izrađenog agensa sušenja pri uslovu da je $\Delta<0$.

Specifična potrošnja apsolutno suvog vazduha u procesu sušenja je:

$$
1_{c}=\frac{1}{x_{2}-x_{1}}
$$

Specifična potrošnja toplote je: 


$$
\mathrm{q}=\frac{\mathrm{h}-\mathrm{h}_{\mathrm{k}}}{\mathrm{x}_{2}-\mathrm{x}_{1}}
$$

$\mathrm{Na}$ sl.2., predstavljen je takođe proces za kondenzacionu sušaru sa kondenzatorom sa mešanjem, analiza pokazuje da on zahteva manju specifičnu potrošnju energije (toplote) pošto je $A_{1}^{\prime} B_{1}\left\langle A_{1} B_{1} A^{\prime}{ }_{1}\right.$.

Međutim suštinski nedostatak ovog procesa je znatna potreba za rashladnom vodom.

Ako se uporedi kondenzaciona sušara sa ranije opisanim, njena osobenost, kako je to istaknuto ranije, je rad bez izmene vazduha, koji se nalazi u samoj komori za sušenje, a u isto vreme u svim drugim varijantama, sušenje se izvodi na račun stalnog odvođenja svežeg vazduha i produkata sagorevanja u komori za sušenje i stalnom ispuštanju iste mase izrađenog agensa sušenja iz komore za sušenje. Međutim, u većini slučajeva na račun ulaska hladnog vazduha kroz procepe komore za sušenje, (nezaptivenost) izdvajanja vlage na površi kondnzatora nema i proces hlađenja i sušenja vazduha u kondenzatoru ide po crtkanoj liniji $\mathrm{CA}^{\prime}{ }_{1}$. Zbog veće složenosti i većih potreba za energijom (toplotnom i električnom) kondenzacione sušare imaju ograničenu primenu. One se koriste, naprimer, u hemijskoj industriji pri sušenju nekih proizvoda, kada je neophodno izdvojiti iz njih štetne primes.

Pri proračunu takvih sušara treba uzeti u obzir da hemijski adsorberbenti pri adsorpciji pare ispuštaju znatnu količinu toplote, skoro jednaku toploti isparavanja, što znači da se u tom slučaju zagrejač računa samo za toplotu neophodnu za pokrivanje gubitaka u okolinu i gubitaka za zagrevanje materijala.

\subsection{Sušare sa toplotnom pumpom}

Proces sušenja se može uspešno ostvariti i primenom toplotne pumpe, koji se bazira na levokretnom termodinamičkom ciklusu. Za razliku od procesa sušenja po zatvorenom ciklusu, toku, ulogu zagrejača preuzima kondenzator dok ulogu hladnjaka isparivač . Glavna razlika u sušarama sa toplotnom pumpom je u činjenici da je razmenjivač toplote, zagrejač uklonjen, a na njegovo mesto je postavljen kodenzator. Kod ovog procesa umesto temperature površi hladnjaka je temperatura površi isparivača.

Na sl. 3a., je prikazano rešenje sušare sa toplotnom pumpom, gde je dat raspored sastavnih komponenti integrisanih sa komorom za sušenje. Vazduh za sušenje prolazeći preko površi kondenzatora se vodi u komoru za sušenje, stanje 1, gde dolazi u kontakt sa materijalom koji se suši i uzima vlagu nastalu isparavanjem iste iz materijala. Nezasićen vlažan vazduh, izrađeni agens sušenja, stanje 2 , se vodi na isparivač. Na isparivaču dolazi do smanjenja, proces od tstanja 2, do stanja 3. Izrađeni agens sušenja se prvo hladi do temperature tačke rose. Rezultat daljeg hlađenja je kondenzacija vodene pare. Ohlađen i osušen izrađeni agens sušenja, vazduh, zatim se vodi na kondenzator, stanja 4 i 1 gde se zagreva do tražene režimske temperature.

Sušare sa toplotnom pumpom mogu biti, sl.3c. sa:otvorenim; poluotvorenim i zatvorenim tokom.
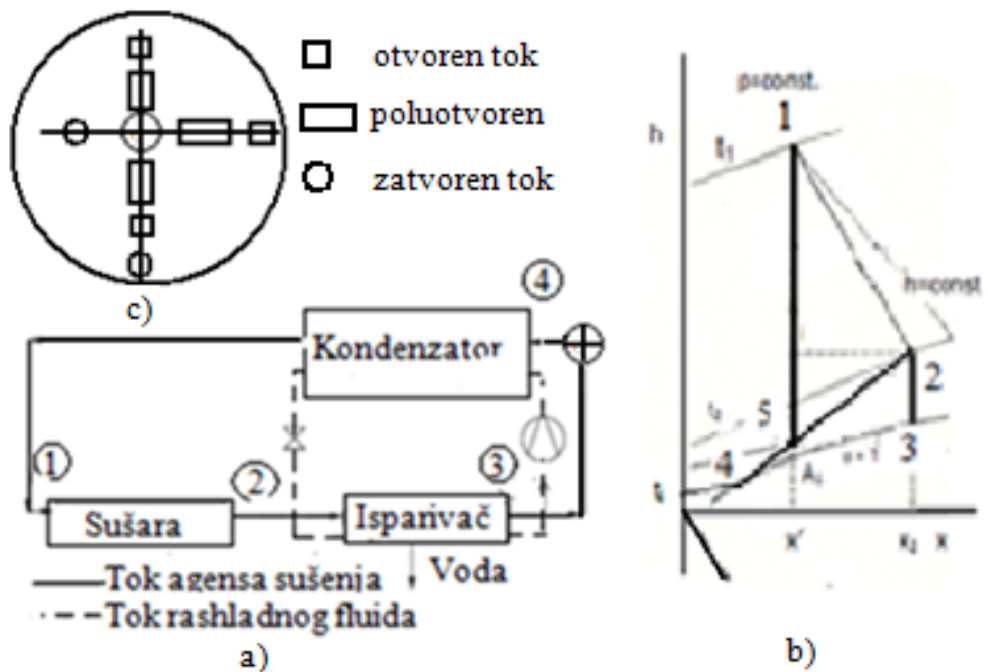

Sl. 3. Sušara sa toplotnom pompom a) i proces sušenja u $x$ - h dijagramu za poluotvoreni tok b)i vrsta toka c) 
Prikaz procesa sušenja sa toplotnom pumpom u $\mathrm{x}$ - h dijagramu je dat na sl.3b.. Kod ovog načina sušenja zagrejan vazduh ulazi u komoru za sušenje, stanje 1 . Kao rezultat njegovog kontakta sa materijalom koji se suši, on se vlaži, stanje 2 . Zatim se ovaj vazduh vodi na isparivač gde se hladi ispod temperature tačke rose, stanje 3, do stanja 4.

Energijska efikasnost toplotne pumpe se definiše faktorom grejanja (COP).

Sem energijske efikasnosti procesa koji karakteriše toplotnu pumpu sa aspekta termodinamičkog procesa (COP), za proces sušenja sa toplotnom pumpom merodavna veličina je specifično izdvajane vlage (SMER), koje je definisano izrazom:

$$
\varepsilon_{W}=\text { SMER }=\frac{\text { masa izdvojene vlage }}{\text { ukupno dovedena energija }}
$$

ili, drugi parametar poznat specifična ,potrošnja” energije SEC, koja je recipročna veličina SMER-a, i može da se koristi za upoređivanje efikasnosti različitih tipova sušara.

Veza između specifične potrošnje energije (SEC) i energijske efikasnosti procesa (COP) je.

$$
\mathrm{SEC}=\frac{Q}{W_{i}}=\frac{\frac{Q_{i}}{(\mathrm{COP})-1}}{L \cdot\left(x_{2}-x_{1}\right)}=\frac{h_{1}-h_{2}}{[(\mathrm{COP})-1] \cdot\left(x_{2}-x_{1}\right)}
$$

Kod sušara sa toplotnom pumpom u odnosu na sušare sa sa zatvorenim tokom nema potrebe za nekim izvorom energije (primer para koja bi se koristila u zagrejaču a time otpada potreba za kotlom za proizvodnju pare kao i toplotna energija za zagrevanje vazduha) jer se ovde koristi električna energija.

\section{Zaključak}

$\mathrm{Na}$ osnovu prikazane analize rešenja za sušenje i odgovarajućih procesa očigledno je da treba praviti razliku između kondnzacione sušare i sušare sa toplotnom pompom i to sa aspekta konstrukcije (strukture) i procesa.

Prema potrošnji toplote i elektroenergije, sušare sa zatvorenim ciklusom i kondenzacijom isparene vode su po pravilu, manje ekonomične od običnih konvektivnih sušara.

Korišćenje delimične recirkulacije izrađenog agensa sušenja u poređenju sa jednoprolaznim korišćenjem agensa sušenja za teorijske procese, koji se odvijaju pri istim ulaznim i izlaznim parametrima, ali različitim početnim temperaturama agensa sušenja, ne obezbeđuje uštedu energije.

Ako se uporede teorijski procesi sušenja sa jednokratnim korišćenjem agensa sušenja i delimičnom recirkulacijom izrađenog agensa sušenja, pri jednakim početnim i krajnjim temperaturama agensa sušenja, u tom slučaju varijanta procesa sa delimičnom recirkulacijom agensa sušenja će zahtevati manju vrednost energije,

Analiza takođe pokazuje da proces za kondenzacionu sušaru sa kondenzatorom sa mešanjem, $u$ odnosu na kondenzacionu sušaru sa površinskim kondenzatorom zahteva manju specifičnu potrošnju energije (toplote). Međutim suštinski nedostatak ovog procesa je značajna potreba za rashladnom vodom.

\section{Literatura}

[1] Topić, M. R.: Osnove projektovanja, proračuna i konstruisanja sušara, „Naučna knjiga”, Beograd, 1989.

[2] Лебедев, Д. П.: Расчет и проектирование сушильных установок, „Государственное энергетическое издательство“ Москва 1963 Ленинрад

[3] Лыков, В. М.: Сушка в химической промышлености, “Химия“, Москва, 1970.

[4] Topić, R.M., Sušenje i higrotermički procesi, Mašinski fakultet, Beograd, 2013. 